\title{
Degree of Conversion of Adhesive Systems Light-Cured By LED and Halogen Light
}

\author{
Cesar Augusto Galvão ARRAIS ${ }^{1}$ \\ Fenelon Martinho PONTES ${ }^{2}$ \\ Luis Presley Serejo dos SANTOS ${ }^{2}$ \\ Edson Roberto LEITE ${ }^{2}$ \\ Marcelo GIANNINI ${ }^{1}$ \\ ${ }^{1}$ Department of Restorative Dentistry, School of Dentistry of Piracicaba, \\ State University of Campinas, Piracicaba, SP, Brazil \\ ${ }^{2}$ Interdisciplinary Laboratory of Electrochemistry and Ceramics, Department of Chemistry, \\ Federal University of São Carlos, São Carlos, SP, Brazil
}

\begin{abstract}
This study evaluated the effect of blue light emitting diode (LED) and quartz tungsten halogen (QTH) on the degree of conversion (DC) of an etch-and-rinse Single Bond adhesive system (SB) and a mixture composed of primer solution and resin bond from Clearfil SE Bond self-etching adhesive system (CB) using Fourier transform infrared analysis (FTIR). Adhesives were applied to potassium bromide pellet surfaces and FTIR analyses were performed before and after photo-activation for $10 \mathrm{~s}$ with either LED (Freelight $1-400 \mathrm{mw} /$ $\left.\mathrm{cm}^{2}\right)$ or QTH (XL $\left.3000-630 \mathrm{mw} / \mathrm{cm}^{2}\right)$ light-curing units $(\mathrm{n}=8)$. Additional FTIR spectra were obtained from photo-activated samples stored in distilled water for 1 week. The DC was calculated by comparing the spectra obtained from adhesive resins before and after photo-activation. The results were analyzed by two-way split-plot ANOVA and Tukey's test $(\mathrm{p}<0.05)$. Both adhesive systems exhibited low DC (\%) immediately after photo-activation (SB/QTH: $18.7 \pm 3.9$; SB/LED: $13.5 \pm 3.3$; CF/QTH: 13.6 \pm 1.9 ; CF/LED: $6.1 \pm 1.0$ ). The DC of samples light-cured with LED was lower than DC of those light-cured with QTH, immediately after light curing and after 1 week (SB/QTH: $51.3 \pm 6.6$; SB/LED: $50.3 \pm 4.8$; CF/QTH: $56.5 \pm 2.9$; CF/LED: $49.2 \pm 4.9$ ). The LED curing unit used to photo-activate the adhesive resins promoted lower DC than the QTH curing unit both immediately after light curing and 1 week after storage in water.
\end{abstract}

Key Words: LED, halogen lamp, degree of conversion, adhesive system.

\section{INTRODUCTION}

For many years quartz-tungsten-halogen bulbs have been used as the lighting source to photo-activate visible-light cured composite resins. However, some factors may compromise the performance of halogen light curing units (LCUs), such as fluctuations in the line voltage, the condition of the bulb and filter, contamination of the light guide, damage to the fiber-optic bundle as well as bulb overheating within the unit. These factors can contribute to reduce the efficiency and lifetime of halogen lamps, leading to poorly polymerized composite resins with impaired mechanical properties (1).

Blue light emitting diode (LED) technology has been indicated as an alternative to conventional halogen lights. LED LCUs consume little power in operating and do not require filters to produce blue light. Moreover, the semiconductors used for light emission instead of hot metal filaments found in halogen bulbs generate less heat and undergo little degradation over time. The gallium nitride LEDs produce a narrow wavelength peak around $470 \mathrm{~nm}$, which matches the absorption peak value of camphorquinone, the most common photoabsorbing compound that initiates the polymerization of resin monomers in dental restorative composites (2).

Some mechanical and physical properties of resin composites light-cured by LED have been reported,

Correspondence: Prof. Dr. Marcelo Giannini, Departamento de Odontologia Restauradora, Faculdade de Odontologia de Piracicaba, UNICAMP, Av. Limeira, 901 13414-903 Piracicaba, SP, Brasil. Tel: +55-19-3412-5338. Fax: +55-19-3412-5218. e-mail: giannini@fop.unicamp.br 
such as compressive and flexural strength, hardness, degree of conversion and depth of cure. Although LED polymerization technology tends to reach the performance level of halogen LCUs (3-6), additional studies are needed to determine the degree of conversion of dental resin-based materials $(7,8)$.

Optimal monomer infiltration into the demineralized collagen network and achievement of high degrees of monomer conversion are crucial factors for establishing long-lasting resin/dentin bonding (9). Some factors might affect the conversion of resin monomer, such as the residual water or organic solvents, and the quality of the light source applied to photo-activate the adhesive systems. Although there are several reports about the effects of LED on composite resins, little-tono studies exist about the efficiency of LED on the degree of conversion of adhesive systems (10). This study evaluated the degree of monomer conversion of two adhesive systems photo-activated with LED and halogen LCUs, using Fourier transform infrared (FTIR) analysis. The null hypothesis was that there is no difference in the degree of conversion when adhesive systems are photo-activated by LED or halogen LCUs.

\section{MATERIAL AND METHODS}

The adhesive systems investigated were: Single Bond (3M/ESPE, St. Paul, MN, USA) and Clearfil SE Bond (Kuraray Medical Inc., Kurashiki, Okayama, Japan). Two commercially available LCUs (Table 1) were tested: XL 3000 halogen-based (3M ESPE - light intensity: 550-630 mw/cm²) and Elipar Freelight 1 LEDbased (3M ESPE - light intensity: $400 \mathrm{mw} / \mathrm{cm}^{2}$ ). Thus, 4 experimental groups $(n=5)$ were formed and evaluated, according to the factors under study (adhesive system and LCU).

For FTIR analysis of Single Bond, one drop of the adhesive resin solution was placed into mixing well. An applicator tip was dipped into adhesive solution and the adhesive was applied to the surface of a potassium bromide pellet. Single Bond adhesive was air dried for 10 $\mathrm{s}$, following the manufacture's instructions, before curing for $10 \mathrm{~s}$. Clearfil SE Bond specimens were prepared by mixing four drops of bonding resin and one drop of primer in a mixing well and air dried for $90 \mathrm{~s}$. One adhesive layer was applied using an applicator tip and light-cured for $10 \mathrm{~s}$. The adhesive systems were light cured without Mylar strip over adhesive layer.

FTIR spectra of non-polymerized adhesive solution were obtained using 20 scans at $4 \mathrm{~cm}^{-1}$ in the transmittance mode (Equinox 55; Bruker Optik GmbH, Ettlingen, Germany). Additional FTIR spectra were obtained immediately after 10-s light-curing and after sample storage in distilled water for 1 week.

For calculating the DC, the aliphatic carbon-tocarbon double bond absorbance peak intensity located at $1638 \mathrm{~cm}^{-1}$ and that for the aromatic component located at $1608 \mathrm{~cm}^{-1}$ (aromatic) were compared in each spectrum before and after the polymerization reaction, and monomer conversion was determined using the following equation (11): $(\% \mathrm{C}=\mathrm{C})=$ [abs (aliphatic $\mathrm{C}$ $=\mathrm{C}$ ) $/$ abs (aromatic C . . .C)] polymer $\div$ [abs (aliphatic $\mathrm{C}=\mathrm{C}$ )/abs (aromatic C ... C)] monomer x 100, where $(\% \mathrm{C}=\mathrm{C})=$ Percentage of remaining carbon double bonds and abs = absorbance.

DC was obtained by subtracting the percentage of remaining carbon double bonds $(\% \mathrm{C}=\mathrm{C})$ from $100 \%$. Conversion data were analyzed by two-way splitplot ANOVA and Tukey's post-hoc test ( $\alpha=0.05$ ).

\section{RESULTS}

Tables 2 to 4 show the DC means and standard deviations for adhesive systems light cured with halogen and LED-based LCUs. Two-way ANOVA revealed that there were statistically significant differences for the factor "adhesive system" ( $p=0.00001)$, for the factor "curing unit" ( $p=0.00001)$ and for factor interactions ( $p=0.01432)$.

Tukey's test showed that the DC of Single Bond

Table 1. Specifications and technical details of the light-curing units used in this study.

\begin{tabular}{lcccc}
\hline Curing unit & Power source & Ligth type & Tip diameter (mm) & Light source \\
\hline XL-3000 & Mains & Quartz tungsten halogen (QTH) & 8 & 1 QTH bulb \\
Elipar Freelight 1 & Battery & Light emitting diode (LED) & 6 & 19 LED in an array \\
\hline
\end{tabular}


was higher than that of Clearfil SE Bond photo-activated with LED-based LCUs. The monomer conversion of both Single Bond and Clearfil SE Bond adhesive systems was affected by LCU type (Table 2). The adhesive systems exhibited low DC immediately after photoactivation with both LCUs (Tables 3 and 4). The DC of specimens light-cured with LED was lower than those light-cured with halogen light, either immediately after light curing or after 1 week of storage (Tables 2 to 4).

Figure 1 shows the spectrum sites obtained from Single Bond and Clearfil SE Bond before and immediately after light curing, as well as after 1 week of storage in water. These sites were used to calculate the DC. Figures $1 \mathrm{~A}$ and $1 \mathrm{~B}$ exhibit the spectrum sites obtained from Single Bond light cured by halogen light and LED LCUs, respectively, while Figures $1 \mathrm{C}$ and $1 \mathrm{D}$ corresponds to the sites from Clearfil SE Bond light cured by halogen light and LED LCUs. There was little reduction in the peak located at $1638 \mathrm{~cm}^{-1}$ after $10 \mathrm{~s}$ of light curing for both adhesive systems. Compared to the spectra obtained from samples immediately after-curing by halogen light,

Table 2. Degree of conversion means $( \pm S D)$ of the adhesive systems after photo-activation with the quartz tungsten halogen $(\mathrm{QTH})$ and light emitting diode (LED)-based curing units.

\begin{tabular}{lll}
\hline & Single Bond & Clearfil SE Bond \\
\hline QTH & $35.0 \pm 5.2 \mathrm{Aa}$ & $35.0 \pm 2.4 \mathrm{Aa}$ \\
LED & $32.0 \pm 4.0 \mathrm{Ba}$ & $27.7 \pm 3.0 \mathrm{Bb}$ \\
\hline
\end{tabular}

Different letters (uppercase - column; lowercase - row) indicate statistically significant difference at $5 \%$ significance level (Tukey’s test).

Table 3. Degree of conversion (DC) means ( \pm SD) of Single Bond after photo-activation with the quartz tungsten halogen (QTH) and light emitting diode (LED)-based curing units.

\begin{tabular}{lcc}
\hline & DC immediately after curing & DC after 1 week \\
\hline QTH & $18.7 \pm 3.9 \mathrm{Aa}$ & $51.3 \pm 6.6 \mathrm{Ab}$ \\
LED & $13.5 \pm 3.3 \mathrm{Ba}$ & $50.3 \pm 4.8 \mathrm{Bb}$ \\
\hline
\end{tabular}

Different letters (uppercase - column; lowercase - row) indicate statistically significant difference at $5 \%$ significance level (Tukey’s test). the spectra obtained from samples light cured with LED demonstrate an apparently smaller reduction in the peak corresponding to carbon-double bonds $\left(1638 \mathrm{~cm}^{-1}\right.$ Figs. 1B and 1D). After 1 week of storage in water, a pronounced reduction in the same peak was observed for both Single Bond and Clearfil SE Bond.

\section{DISCUSSION}

The degree of monomer conversion depends on the output and wavelength of the light, exposure time and composition of light-activated resin-based material. In this study, the tested resin-based materials were adhesive systems, that were light cured with two commercially available LCUs. The results indicated that the LED-based LCU did not polymerize the adhesive systems at different times of post-light curing like conventional halogen lamps do, therefore, the null hypothesis was rejected.

One possible reason for this result may be the difference in light intensities. The light intensity of the halogen LCU evaluated in this study is about $600 \mathrm{~mW} /$ $\mathrm{cm}^{2}$, while the LED LCU has light intensity of approximately $400 \mathrm{~mW} / \mathrm{cm}^{2}$. The higher light intensity promotes higher wavelength peak at $470 \mathrm{~nm}$ and more camphorquinone molecules will be excited. As a consequence, more free radicals are generated and faster monomer conversion will occur, resulting in higher DC in shorter time (12). Some studies have suggested that halogen light still produce greater curing energy and higher degree of composite monomer conversion than the first generation of LED lights $(7,8,13)$.

Halogen LCUs generate heat during operation, increasing the temperature on the surface. Based on the

Table 4. Degree of conversion (DC) means ( \pm SD) of Clearfil SE Bond after photo-activation with the quartz tungsten halogen (QTH) and light emitting diode (LED)-based curing units.

\begin{tabular}{lcc}
\hline & DC immediately after curing & DC after 1 week \\
\hline QTH & $13.6 \pm 1.9 \mathrm{Aa}$ & $56.5 \pm 2.9 \mathrm{Ab}$ \\
LED & $6.1 \pm 1.0 \mathrm{Ba}$ & $49.2 \pm 4.9 \mathrm{Bb}$
\end{tabular}

Different letters (uppercase - column; lowercase - row) indicate statistically significant difference at $5 \%$ significance level (Tukey's test). 
fact that the adhesive systems are spread into a layer thinner than that of restorative composites prior light curing (10), the rise of surface temperature that occurs during polymerization can additionally improve the rate of polymerization. The heat can be absorbed, increasing the molecular movements and the collisions, which can contribute to increase the DC $(1,6,14,15)$.

A great amount of unpolymerized monomers from Clearfil SE Bond adhesive were detected by FTIR analysis immediately after LED photo-activation. Regardless of the lower power density emitted by LED $(7,8,13)$, differences in resin adhesive composition and sample preparation might have affected the DC when LED LCU was tested. The mixture of Bond and Primer of Clearfil SE Bond results in a solution with low $\mathrm{pH}$ (approximately 2) and high water content, which can impair the polymerization reaction of the adhesive. The
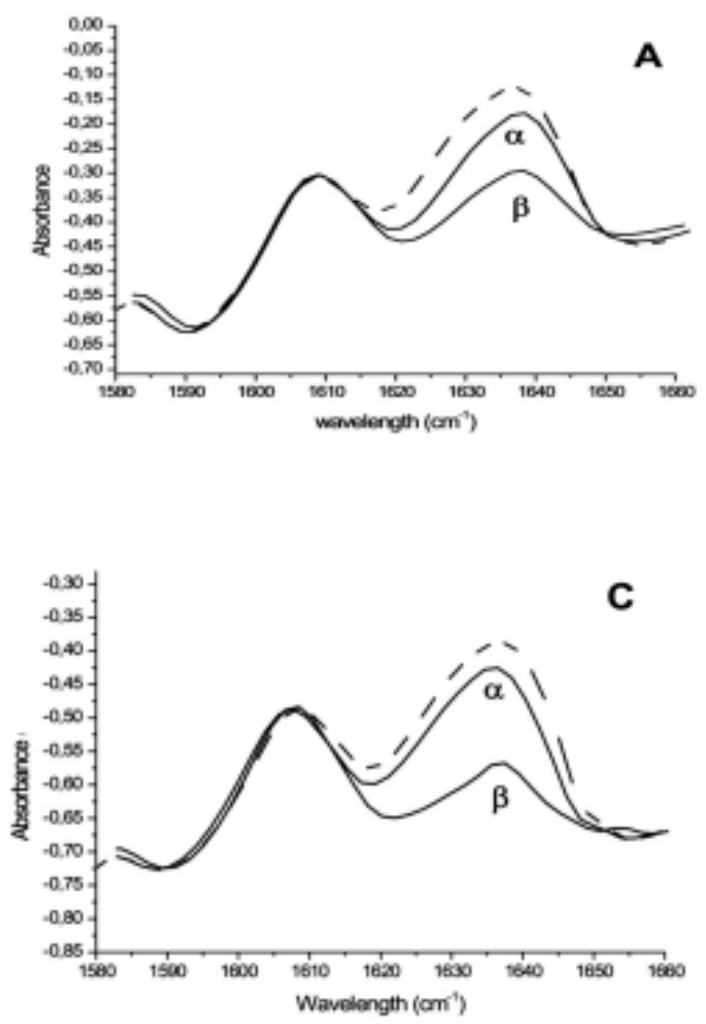

Clearfil SE Bond samples were composed of the mixture of four drops of Bond and one drop of Primer in an attempt to reduce the water content and increase the monomer $\mathrm{pH}$ that allows the polymer conversion to occur. When applied to tooth surface, the self-etching primer acidity can be buffered by mineral content of dentin and enamel (18), allowing the higher monomer conversion. The changes for preparations of Clearfil SE Bond samples, such as reduction of the water content from Primer solution and the increase in Bis-GMA content, might have altered the adhesive material, which would modify the maximal rate of conversion and the result of the polymerization reaction (19).

Like when adhesive systems are applied clinically, the contact between resin adhesive and atmospheric oxygen was not avoided during the photoactivation of adhesive samples $(16,17)$. This might
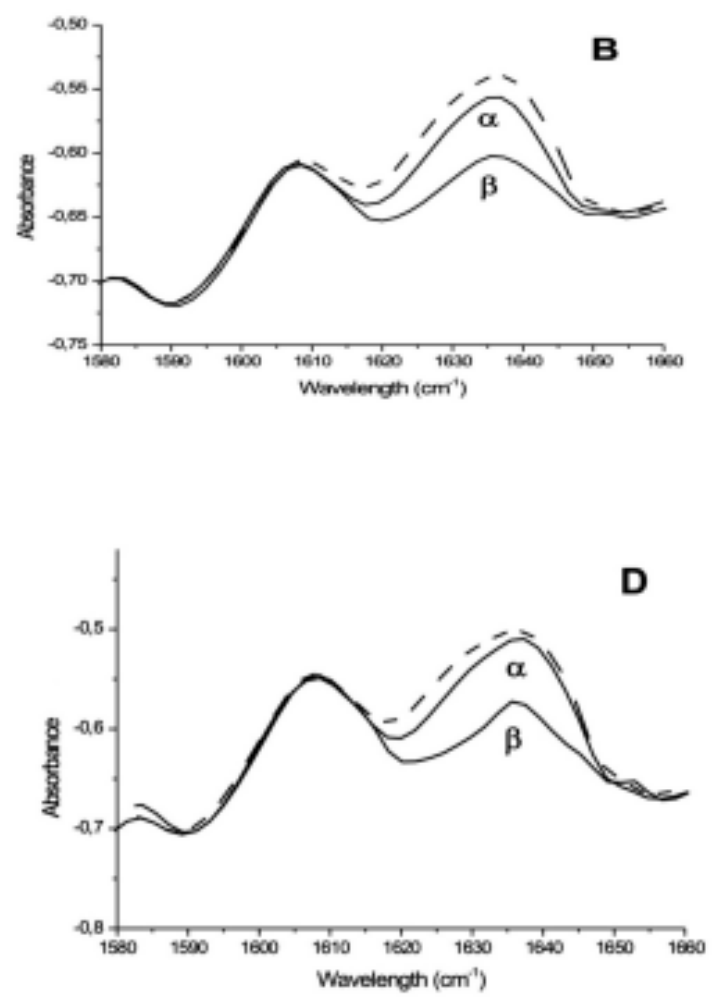

Figure 1. FTIR spectrum sites obtained from Single Bond and Clearfil SE Bond adhesive resins before light exposure (dotted line), immediately after light exposure $(\alpha)$ and after 1 week $(\beta)$. Little reduction in the peak located at $1638 \mathrm{~cm}^{-1}$ was observed immediately after light exposure $(\alpha)$ when Single Bond was light-cured with halogen light (A) or LED (B). FTIR analysis of Clearfil SE Bond exhibited similar reduction when halogen light was applied (C), while this reduction was less pronounced when LED was used (D). After 1 week, FTIR analysis of all samples exhibited a pronounced reduction in the same peak ( $\beta$ ). 
explain the low DC observed in the thin cured adhesive layers immediately after light exposition by both LCUs tested. Thus, an uncured adhesive layer affected by oxygen inhibition may form poor polymer chain in the hybrid layer, reducing the longevity of tooth-composite bonding (9).

On the other hand, FTIR analysis of adhesive samples after 1 week exhibited a pronounced DC increase compared to the initial values for both LCUs used and adhesive systems evaluated. A possible explanation was that the polymerization reaction might last for periods longer than $24 \mathrm{~h}$ (12). Moreover, based on the fact that incomplete conversion of monomers could result in increased adhesive resin solubility, the water immersion could lead to the removal of the oxygen-inhibited resin layer from the surface of lightedcured samples stored for one week (20). Therefore, FTIR analysis of samples without uncured layer will only count the amount of residual carbon double bonds from the cured layer and those from the uncured layer that can be also covalently bound to the polymer chain with further potential to react chemically and cannot leach out (1).

Within the limitations of the methodology employed in this study, it may be concluded that the measurements of the degree of monomer conversion showed that LED LCU did not produce similar performance level of conventional halogen LCU for adhesive systems tested. Considering the low initial degree of adhesive monomer conversion into polymer and LED LCU performance, concerns regarding the formation of high quality hybridization zones arise when the adhesive systems are applied to deep or unfavorable cavity preparations where curing energy decreases significantly. This condition can have clinical significance on the durability of the adhesive.

\section{RESUMO}

Este estudo avaliou a influência de sistemas de fotoativação no grau de conversão (GC) de sistemas adesivos por meio da análise infravermelha transformada de Fourier (FTIR). Os sistemas adesivos Single Bond(SB) e Clearfil SE Bond(CF) foram aplicados em pastilhas de brometo de potássio e fotoativados com luz halógena (XL 3000-630 mw/ $\mathrm{cm}^{2}$ ) (QTH) e LED (Elipar Freelight $\left.1-400 \mathrm{mw} / \mathrm{cm}^{2}\right)$ por $10 \mathrm{~s}(\mathrm{n}=8)$. Foram obtidos espectros de FTIR antes e imediatamente após a fotoativação, e tambem após 1 semana de armazenamento em água destilada. Calculou-se o GC comparando-se a razão entre os picos das bandas dos espectros, antes e após a fotoativação. Os resultados de GC foram submetidos à ANOVA e ao teste de Tukey $(\mathrm{p}<0,05)$. Para ambos os sistemas adesivos, o GC (\%) obtido imediatamente após a fotoativação com LED foi inferior ao obtido utilizando-se QTH (SB/QTH: 18,7 \pm 3,9; SB/LED: 13,5 \pm 3,3; CF/QTH: 13,6 \pm 1,9; CF/LED: $6,1 \pm 1,0)$. Após uma semana foi observado um aumento significativo no GC de todos os grupos, porém os valores dos grupos fotoativados com LED mantiveram-se inferiores aos obtidos com QTH (SB/QTH: 51,3 \pm 6,6; SB/LED: 50,3 \pm 4,8; CF/QTH: 56,5 \pm 2,9; CF/LED: 49,2 $\pm 4,9$ ). O GC dos adesivos fotoativados com LED foi inferior ao observado após fotoativação com QTH, imediatamente após fotoativação como após 1 semana de armazenamento em água.

\section{ACKNOWLEDGEMENTS}

This study was supported by a grant-in-aid from FAPESP \# 03/ 03645-0.

\section{REFERENCES}

1. Rueggeberg FA. Contemporary issues in photocuring. Compend Contin Educ Dent 1999;20:S4-15. Suppl. 25.

2. Burgess JO, Walker RS, Porche CJ, Rappold AJ. Light curing an update. Compend Contin Educ Dent 2002;23:889-906.

3. Stahl F, Ashworth SH, Jandt KD, Mills RW. Light-emmiting diode (LED) polymerization of dental composites: flexural properties and polymerization potential. Biomaterials 2000;21:1379-1385.

4. Jandt KD, Mills RW, Blackwell GB, Ashworth SH. Depth of cure and compressive strength of dental composites cured with blue light emitting diodes. Dent Mater 2000;16:41-47.

5. Nomura Y, Teshima W, Tanaka N, Yoshida Y, Nahara Y, Okazaki M. Thermal analysis of dental resins cured with blue light-emitting diodes. J Biomed Mater Res 2002;63:209-213.

6. Hofman N, Hugo B, Klaiber B. Effect of irradiation type (LED or QTH) on photo-activacted composite shrinkage strain kinetics, temperature raise and hardness. Eur J Oral Sci 2002;110:471-479.

7. Knezevic A, Tarle Z, Meniga A, Sutalo J, Pichler G, Ristic M. Degree of conversion and temperature rise during polymerization of composite resin samples with blue diodes. J Oral Rehabil 2001;28:586-591.

8. Dunn WJ, Bush AC. A comparison of polymerization by light-emitting diode and halogen-based light-curing units $\mathrm{J}$ Am Dent Assoc 2002;133:335-341.

9. Reis AF, Arrais CAG, Novaes PD, Carvalho RM, De Goes MF, Giannini M. Ultramorphological analysis of resin-dentin interfaces produced with water-based single-step and two-step adhesives: nanoleakage expression. J Biomed Mater Res 2004;71B:90-98.

10. De Goes MF, Giannini M, Rueggeberg FA. Conversion of dentin bonding agents mixed with composite. J Dent Res 2004;83:SI [Abstract 556].

11. Ferracane JL, Greener EH. Fourier transform infrared analysis of degree of polymerization in unfilled resins-methods comparison. J Dent Res 1984;63:1093-1095.

12. Halvorson RH, Erickson RL, Davidson CL. Energy dependent polymerization of resin-based composite. Dent Mater 2002;18:463-469.

13. Nomoto R. Effect of light wavelength on polymerization of 
light-cured resins. Dent Mater J 1997;16:60-73.

14. Kloosterboer JG, Van de Hei GMM, Gossink RG, Dortant GCM. The effects of volume relaxation and thermal mobilization of trapped radicals on the final conversion of photopolymerized diacrylates. Polymer Comm 1984;25:322-325.

15. Wendt Jr SL. The effect of heat used as a secondary cure upon the physical properties of three composites resins. I. Diametral tensile strength, compressive strength and marginal dimensional stability. Quintessence Int 1987;18:265-271.

16. Ruyter IE. Unpolymerized surface layers on sealants. Acta Odontol Scand 1981;39:27-32.

17. Rueggeberg FA, Margenson DH. The effect of oxygen inhibi- tion on an unfilled/filled composite system. J Dent Res 1990;69:1652-1658.

18. Tay FR, Pashley DH. Aggressiveness of contemporary selfetching systems. I. Depth of penetration beyond dentin smear layers. Dent Mater 2001;17:296-308.

19. Sideridou I, Tserki V, Papanastasiou G. Effect of chemical structure on degree of conversion in light-cured dimethacrylatebased dental resins. Biomaterials 2002;23:1819-1829.

20. Pearson GJ, Longman CM. Water sorption and solubility of resin-based materials following inadequate polymerization by a visible-light curing system. J Oral Rehabil 1989;16:57-61.

Accepted September 4, 2006 